\title{
MANAGENT of Human Resources
}

\author{
Elham Fakourifard \\ Bachelor of Business Management, Shiraz Branch, Islamic Azad University \\ conferenceseventsoffice@gmail.com
}

\begin{abstract}
This paper proposes linkages between human resource (HR) systems, relational climates and employee helping behavior. We suggest HR systems promote relational climates varying in terms of the motivation and sustenance of helping behavior. HR systems are expected to indirectly influence the nature of relationships and the character of helping within organizations.
\end{abstract}

KEYWORDS: Management, Achieves, Employment.

\section{INTRODUCTION}

At the heart of theoretical and empirical work on helping behavior in organizations is the notion that organizations often depend on such behaviors to deal with non-routine aspects of work. Helping behavior is a robust predictor of group and organizational performance (Podsakoff, MacKenzie, Paine, \& Bachrach, 2000), and has become more important in light of movement toward greater employee involvement (e.g., Boxall \& Macky, 2009), interactive work structures (e.g., Frenkel \& Sanders, 2007), and human resource flexibility within organizations (e.g., Beltrán-Martín, Roca-Puig, Escrig-Tena, \& Bou-Llusar, 2008). As helping behavior involves actions by which individuals positively affect others, much organizational research has sought to identify its immediate dispositional and situational antecedents. Less work has been devoted toward establishing broader mechanisms organizations can use to harness these antecedents (Organ, Podsakoff, \& MacKenzie, 2006).

Three Archetypal HR Systems Lepak, Bartol, and Erhardt (2005) suggested focusing on the purpose of HR systems when defining them. Two contrasting archetypal alternatives, each representing a distinct approach to managing human resources, have been widely discussed. A compliance system views employees as extrinsically motivated commodities. As such, it seeks to establish control and efficiency in the administration and deployment of the workforce (Walton, 1985).

Alternatively, a commitment system views employees and the organization as having a high regard for one another - much like family or clan members (Ouchi, 1980). Its goal is to elevate employee performance by bolstering this collective commitment. In addition to these two alternatives, Lepak and Snell (1999) have discussed a collaboration-based HR system, aspects of which entail more of a partnership with employees. Building on their reasoning, we conceptualize a collaboration system as one in which employees are viewed as members in alliance with the organization. Using Lepak and Snell (1999) as our guide, we define each HR system in terms of elements supporting and reinforcing the characteristic employment relationship (i.e., whether the implied psychological contract between the organization and employees is transactional, balanced, or relational; see Rousseau, 1995) and employment mode (i.e., whether human capital acquisition and development is more internal or external to the 
organization). Although the three HR systems discussed are theoretically derived, research indicates there are strategic reasons for implementing them and empirical support for their existence in organizations (e.g., Arthur, 1994; Lepak \& Snell, 2002; Tsui, Pearce, Porter, \& Tripoli, 1997).

We maintain that the emergent relational climate experienced by employees working within a particular HR system will be a function of the two system elements (i.e. employment relationship and employment mode) and practices enacted to operationalize these elements. HR practices have been discussed as having secondary signaling influences on employees' psychological contracts with organizations (e.g., Rousseau, 1995), and a recent comprehensive literature review concluded that HR practices substantially determine such contracts (Suazo, Martinez, \& Sandoval, 2009). Research also suggests that in evaluating psychological contracts, employees rely on information from coworkers (Ho \& Levesque, 2005). We are unaware of empirical evidence showing that HR systems directly affect employees' sensemaking about relationships with one another, but there is theoretical support for this notion (e.g., Bowen \& Ostroff, 2004; Ferris, Arthur, Berkson, Kaplan, Harrell-Cook, \& Frink, 1998).

\section{GENERAL MANAGEMENT of Human Resources All Over the World}

In general, HR management has been extensively decentralized. Most of the EU member states have moved towards some degree of decentralization of HR responsibilities, from central publicsector body to local ministries and public administrations. There is a tendency to delegate HR practices to local public administrations. This allows the various public administrations more autonomy and flexibility in their daily HR management. Local public administrations can deal with their HR issues and tools following the central body strategies and regulations. The structure of the Austrian HR organization is not entirely decentralized, but a mix between a centralized and a decentralized system. In the future, the main challenge for governments will be to find ways of maintaining consistency while transferring on some HR responsibilities.

Yet, the extent and rapidity of delegation is different between the various EU member states because there are differences between position-based systems (Denmark, Finland, Sweden, UK, Austria) and career-based systems (Luxembourg, Germany, France, Spain, Greece, Hungary). The variety of environments (political, economical, culture) has an impact on the way HR has been decentralized. A position-based system, being more decentralized than the career-based system, gives more flexibility and allows an individualized approach to Human Resources Management. There are also countries characterized by a "hybrid system", presenting elements from the position-based and career-based systems (like Italy). In these countries there is a relatively high level of delegation, giving a lot of responsibilities to line ministries in the definition and practices of Human Resources Management policies, and a relatively low level of individualization in the approach to Human Resources Management.

The various forms of political and economical models across Europe have an influence on the management of relations between workers and employers. These differences influence Human Resources Management.

\section{HR Processes and Practices}

As specified previously, the survey results indicate that government and HR strategies are focused towards modernization, improving the quality of services, satisfaction of the citizen, mobility and flexibility of civil servants, work quality, leadership developments.... HR processes such as recruitment and career management are therefore essential in supporting these strategies. 
DOI : https://dx.doi.org/10.26808/rs.aj.i7v1.02

The recruitment of skilled staff and their subsequent career management focus on "selecting" and "developing" people who bring to public institutions the skills and competences to attain the strategies decided.

In fact, in order to reach a certain level of quality of services and innovation, the right people should be found and developed. As stated by the President of the European Commission, José Manuel Barroso, "our clear aim is to achieve more and better jobs in a more dynamic, innovative and attractive Europe. With this strategy I believe we now have the right tools to achieve our goals."

\section{Recruitment}

Recruitment is important because other HR policies are heavily dependent on the effectiveness of this process. One of HR challenges is identifying, motivating and retaining talent. Recruitment is attracting the right skills to do the job. Yet, the public service, just like the private sector, has to compete in the "search for talent" in the face of demographic change. The public sector has to compete with everyone else for attracting talent. The "search for talent" is not to compete for a mass of numerous talents but rather to target for key individuals, focusing then on continued development of people who are going to be the leaders of the future. The society is asking people to do more efforts to prevail over enormous organizational and economical challenges. Unfortunately today fewer people have the combination of right skills that institutions need. Thus HR has

- To have a good understanding of government issues,

- To locate talent that can help achieve the goals,

- To develop and retain that talent.

\section{RECORDS MANAGEMENT ACCESS RESTRICTIONS}

a. Records with active administrative value will be stored in the College Records Management repositories whether physical or electronic. These records shall only be made accessible to those individuals within the originating department who have been approved for such access by the department's Records Custodian. Access by other College officials can be arranged on a caseby-case basis. No records under the control of Records Management are ever shared outside of these limitations, especially to those outside of the institution accept as required by law.

b. Stored records may be retrieved from the Records Management repository by authorized users, as defined above.

c. Records Management staff will only consult the internal contents of individual files or documents in Records Management repositories when specifically requested to do so by authorized users, as defined above.

\section{ARCHIVES ACCESS RESTRICTIONS}

a. Physical archival records are restricted to onsite use at Rauner Special Collections Library.

b. College archival records, other than widely distributed public documents such as catalogs, handbooks, publicity photographs, etc., will normally remain closed for a maximum period of twenty-five years from the date of their creation pursuant to the General Restrictions Statement. The opening date for access to files spanning several years will be twenty-five years from the 
DOI : https://dx.doi.org/10.26808/rs.aj.i7v1.02

most recent date. Access will be given to records already twenty-five years old contained within a records series that is not yet open only when such material can easily be isolated from the rest of the records series.

Records that are closed for a longer period are the following:

i. Board of Trustees records, including committees of the Board, are closed for 50 years from date of their creation.

ii. Records of a sitting President are closed. The records of past administrations are closed for a period of 25 years after the President has left office.

iii. In accordance with The Family Educational Rights and Privacy Act (FERPA) (20 U.S.C. § 1232g; 34 CFR Part 99) student records are closed for 75 years from the date of record creation or until decease of the individual, whichever comes first.

iv. Personnel records are closed for 75 years from date of their creation, or until decease of the individual, whichever comes first.

c. Other records may be restricted for more than twenty-five years at the request of the office of origin per review of the Records Retention Committee and/or the President of the College or a Presidential designee.

d. During the restricted period, the records will be available only to the President's Office, the office of origin, and the staff of the Archives and Special Collections. Consideration will be given for access by other offices and departments within the College to facilitate administrative functions. Researchers unaffiliated with the College may make written request for access to the College Archivist. The Archivist, in consultation with the appropriate officer in the office of origin or the appropriate College officer now responsible for the function performed by the office of origin, will determine whether access to such records will be granted.

e. The records will be made available in accordance with the rules and regulations of the Archives, a department of the Dartmouth College Library, and Federal and State regulations.

f. This policy will not impinge upon the normal administrative uses of College records.

GENERAL RESTRICTION STATEMENT

These restrictions apply even after Archives Access Restrictions expire

The Dartmouth College Archives is committed to making research records available to users on equal terms of access. This is in accordance with the standard professional policy on access adopted jointly by the Society of American Archivists and the American Library Association (ALA-SAA Joint Statement on Access: Guidelines for Access to Original and Research Materials, 1994.). Equal access does not mean that all records are open to research use. It is the responsibility of the Archives to balance a researcher's needs for access with the need for confidentiality of persons and institutions whose activities are reflected in the materials. 
Consequently, the use of some records in the Archives, especially those of recent date, are subject to restrictions.

Two types of restrictions exist. Restrictions on access that apply to more than one group of records are termed "General Restrictions." General restrictions are applicable to particular kinds of information or designated classes of materials, wherever they may be found among the holdings. The other types of restrictions are known as "Specific Restrictions." These are restrictions specified by the transferring office or agency, or donor and apply to a specific body of material, sometimes for a specific length of time. Information about specific restrictions will be found in the deed of gift or accession record that covers the body of records to which the specific restriction applies. It should be noted that General Restrictions supersede Specific Restrictions and may cause records that have passed out of a specific restriction to remain restricted for extended time period.

\section{Conclusion}

Human resources is the most important factor to doing tasks in each company, organization or factory. The purpose of the survey could provide the employer with valuable insight into the work environment and factors that may have influenced the employee's departure in some way. The results and outcomes of the survey could also feed in to the enhancement of recruitment and retention strategies in the public service for future human resource planning.

In the case of the Exit Survey, it is important to avail of the opportunity while the employee is still with the public service, while ensuring complete confidentiality of the employee's feed back through neutral, third-party involvement. Managing human resources under a studied developed and scientific circumstances program using mechanisms helps progressing in the organization.

\section{REFERENCES}

I. Ames, D. R., Flynn, F. J., \& Weber, E. U. 2004. It's the thought that counts: On perceiving how helpers decide to lend a hand. Personality and Social Psychology Bulletin, 30: 461-474.

II. Anderson, S. E., \& Williams, L. J. 1996. Interpersonal, job, and individual factors related to helping processes at work. Journal of Applied Psychology, 81: 282-296.

III. Arthur, J. B. (1994). Effects of human resource systems on manufacturing performance and turnover. Academy of Management Journal, 37: 670-687.

IV. Bacharach, S. B., Bamberger, P. A., \& McKinney, V. 2000. Boundary management tactics and logics of action: The case of peer-support providers. Administrative Science Quarterly, 45: 704-736.

V. Bamberger, P. A. 2008. Beyond contextualization-Using context theories to narrow the micromacro gap in management research. Academy of Management Journal, 51: 839846.

VI. Bamberger, P. A. 2009. Employee help-seeking: Antecedents, consequences and new insights for future research. Research in Personnel and Human Resources Management, 29: 49-98.

VII. Tsui, A. S., Pearce, J. L., Porter, L. W., \& Tripoli, A. M. 1997. Alternative approaches to the employee-organization relationship: Does investment in employees pay off? Academy of Management Journal, 40: 1089-1121. 
DOI : https://dx.doi.org/10.26808/rs.aj.i7v1.02

American Journal of Sustainable Cities and Society

Issue 7, Vol. 1 January- December 2018

Available online on http://www.rspublication.com/ajscs/ajsas.html

ISSN $2319-7277$

VIII. Van der Vegt, G. S., \& Van de Vliert, E. 2005. Effects of perceived skill dissimilarity and task interdependence on helping in work teams. Journal of Management, 31: 73-89.

IX. Van Dyne, L., \& LePine, J. A. 1998. Helping and voice extra-role behaviors: Evidence of construct and predictive validity. Academy of Management Journal, 41: 108-119.

X. Venkataramani, V., \& Dalal, R. S. 2007. Who helps and harms whom? Relational antecedents of interpersonal helping and harming in organizations. Journal of Applied Psychology, 92: 952-966.

XI. Wageman, R., \& Baker, G. 1997. Incentives and cooperation: The joint effects of task and reward interdependence on group performance. Journal of Organizational Behavior, 18: $139-158$.

XII. Wang, H. C., He, J., \& Mahoney, J. T. 2009. Firm-specific knowledge resources and competitive advantage: The roles of economic- and relationship-based employee governance mechanisms. Strategic Management Journal, 30: 1265-1285. 